Prepared in cooperation with U.S. Fish and Wildlife Service, Bureau of Land Management, and U.S. Forest Service

\title{
Effects of Experimental Removal of Barred Owls on Population Demography of Northern Spotted Owls in Washington and Oregon-2016 Progress Report
}

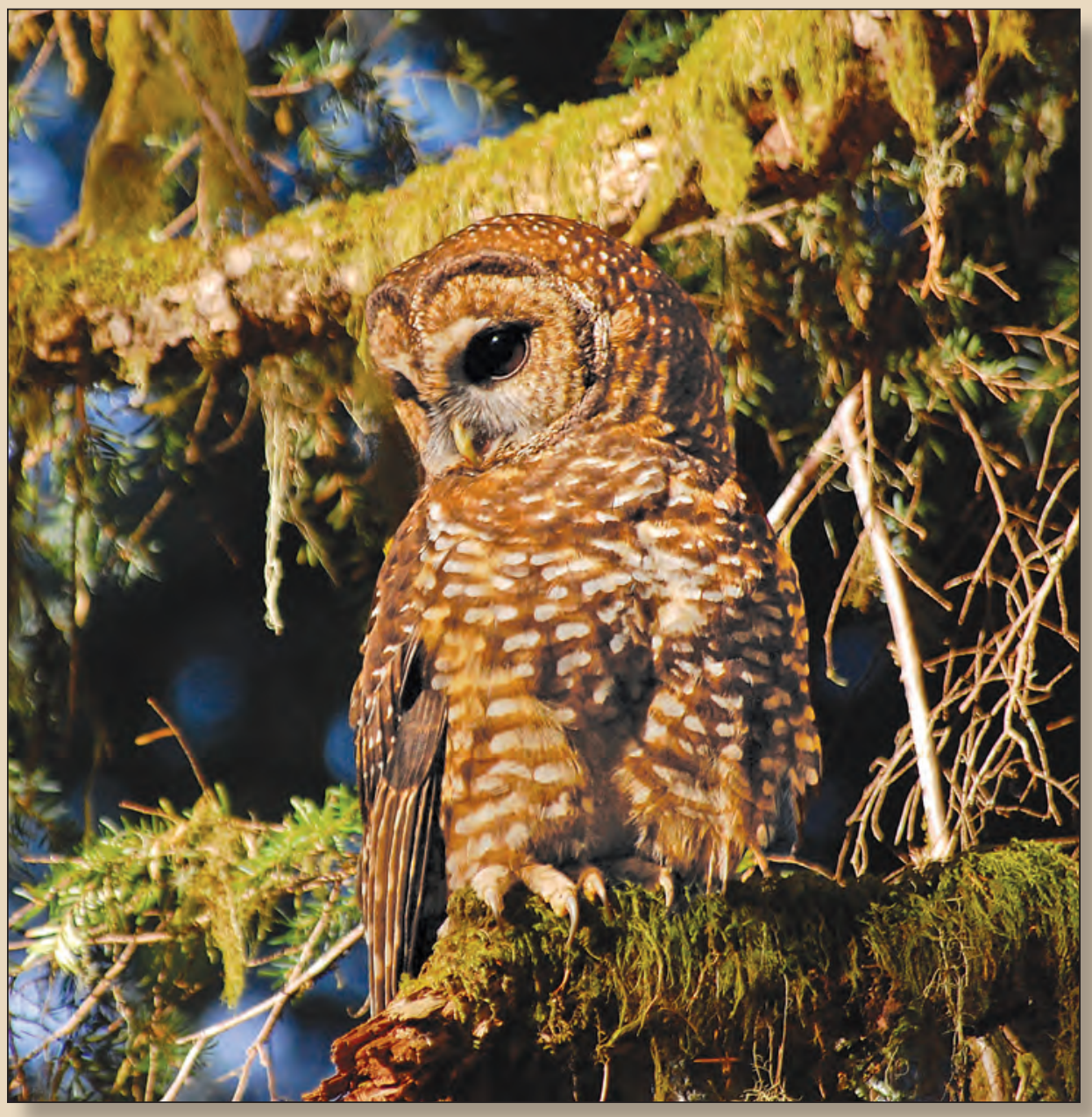

Open-File Report 2017-1040

U.S. Department of the Interior

U.S. Geological Survey 
Cover: Photograph of northern spotted owl (Strix occidentalis caurina).

Photograph by Kristian Skybak, Oregon State University. Used with permission. 


\section{Effects of Experimental Removal of Barred Owls on Population Demography of Northern Spotted Owls in Washington and Oregon-2016 Progress Report}

By J. David Wiens, Katie M. Dugger, Krista E. Lewicki, and David C. Simon

Prepared in cooperation with U.S. Fish and Wildlife Service, Bureau of Land Management, and U.S. Forest Service

Open-File Report 2017-1040

U.S. Department of the Interior

U.S. Geological Survey 


\section{U.S. Department of the Interior \\ RYAN K. ZINKE, Secretary}

\section{U.S. Geological Survey \\ William H. Werkheiser, Acting Director}

For more information on the USGS—-the Federal source for science about the Earth, its natural and living resources, natural hazards, and the environment-visit https://www.usgs.gov or call 1-888-ASK-USGS (1-888-275-8747).

For an overview of USGS information products, including maps, imagery, and publications, visit https:/store.usgs.gov.

Any use of trade, firm, or product names is for descriptive purposes only and does not imply endorsement by the U.S. Government.

Although this information product, for the most part, is in the public domain, it also may contain copyrighted materials as noted in the text. Permission to reproduce copyrighted items must be secured from the copyright owner.

Suggested citation:

Wiens, J.D., Dugger, K.M., Lewicki, K.E., and Simon, D.C., 2017, Effects of experimental removal of barred owls on population demography of northern spotted owls in Washington and Oregon-2016 progress report: U.S. Geological Survey Open-File Report 2017-1040, 23 p., https://doi.org/10.3133/ofr20171040. 


\section{Contents}

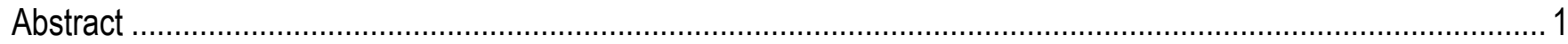

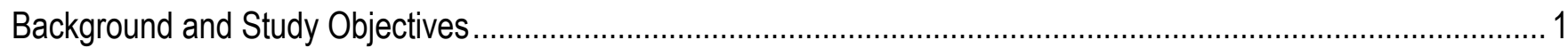

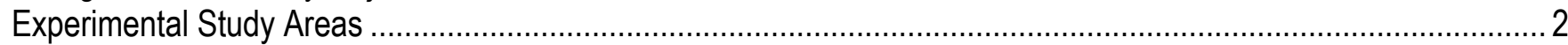

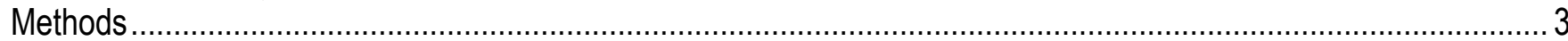

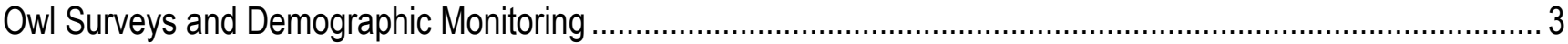

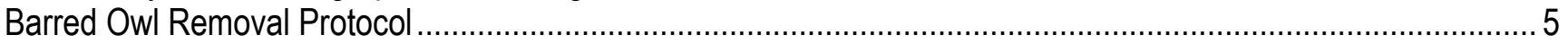

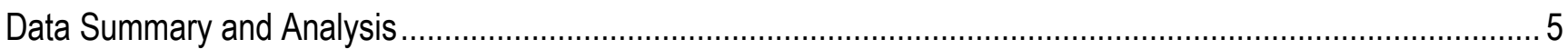

Probability of Barred OwI Use in Control and Treatment Areas.................................................................. 6

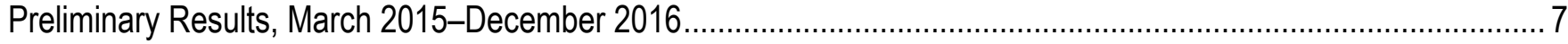

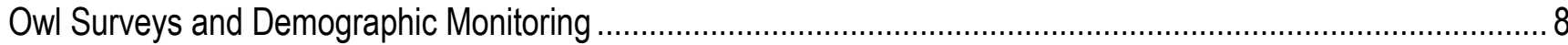

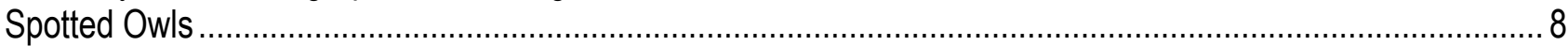

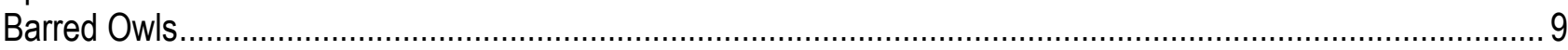

Probability of Barred Owl Use in Control and Treatment Areas .................................................................. 10

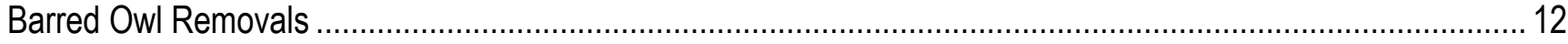

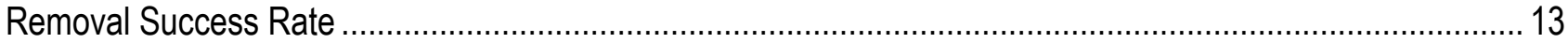

Age of Recolonizing Barred Owls ................................................................................................. 14

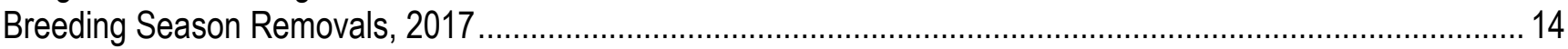

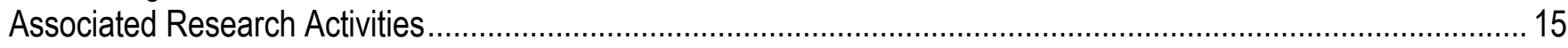

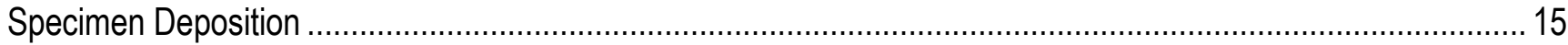

Assessment of Barred Owl Rodenticide Exposure .............................................................................. 15

Barred Owl Diets and Effects on Other Species................................................................................ 15

Demographic Simulation Models of Species Interactions to Guide Barred Owl Removal Strategies .................... 15

Development of a Standardized Aging Method for Barred Owls ................................................................ 15

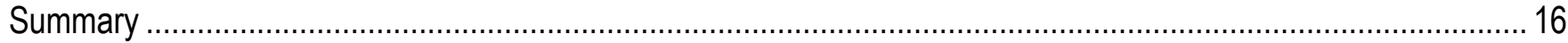

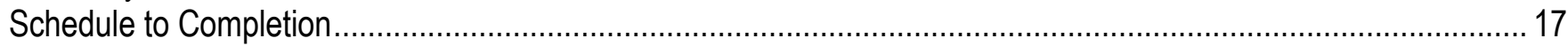

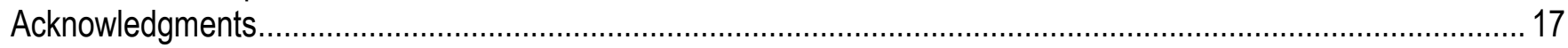

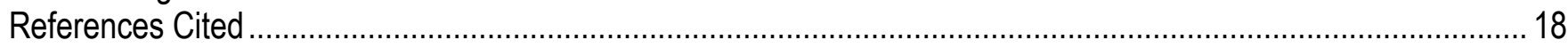

Appendix A. Distribution of Pairs of Northern Spotted Owls and Barred Owls in Three Experimental

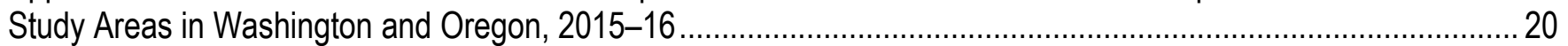

Appendix B. Model Selection Results for the Analysis of Probabilities of Use ( $\psi)$, Extinction $(\varepsilon)$,

Colonization $(\gamma)$, and Detection $(p)$ of Barred Owls on the Cle Elum Experimental Study Area,

Washington, 2015-16

Appendix C. Model Selection Results for the Analysis of Probabilities of Use $(\psi)$, Extinction $(\varepsilon)$,

Colonization $(\gamma)$, and Detection $(p)$ of Barred Owls on the Coast Ranges Experimental Study Area, Oregon, 2015-16

Appendix D. Model Selection Results for the Single-Season Analysis of Probabilities of Use $(\psi)$ and

Detection ( $p$ ) of Barred Owls on the Klamath/Union/Myrtle Experimental Study Area, Oregon, 2016.

\section{Figures}

Figure 1. Control (no barred owls removed) and treatment (barred owls) portions of three study areas used to examine the effects of experimental removal of barred owls on population demography of northern spotted owls in Washington and Oregon.

Figure 2. Example of overlap between sites surveyed for northern spotted owls (historical territories) and barred owls (500-hectare survey hexagons) in the Coast Ranges experimental study area, Oregon. 
Figure 3. Timeline of barred owl survey (white) and removal (black) efforts in the Cle Elum, Coast Ranges, and Klamath/Union/Myrtle experimental study areas, Washington and Oregon, 2015-16 ....

Figure 4. Mean number of barred owl (a) individuals and (b) pairs detected per survey site (500-hectare hexagon) in control and treatment areas of the Cle Elum (CLE) and Coast Ranges (COA) study areas, Washington and Oregon, 2015-16.

Figure 5. Total numbers of barred owls detected versus removed during field visits to the Cle Elum and Coast Ranges experimental study areas, Washington and Oregon September 2015-December 2016.

Figure 6. Change in the proportion of barred owls collected that were either adults ( 3 years or older) or subadults (1-2 years old) during the first 16 months after removals were initiated on three study areas, Washington and Oregon, 2015-16.

\section{Tables}

Table 1. Northern spotted owl survey effort, detections at historically occupied territories, and observed reproduction on treatment (barred owls removed) versus control (barred owls not removed) portions of three experimental study areas, Washington and Oregon, 2015-16.

Table 2. Barred owl survey and detections at sites (500-hectare survey hexagons) on treatment (barred owls removed) versus control (barred owls not removed) portions of three experimental study areas, Washington and Oregon, 2015-16

Table 3. Model-averaged estimates, with standard errors (SE) and lower (LCl) and upper (UCI) 95-percent confidence intervals, of the probability of use by territorial pairs of barred owls $(\hat{\bar{\psi}})$, and annual rate of change in the probability of use $(\hat{\bar{\lambda}})$, in two experimenl study areas, Oregon and Washington, 2015-16.

Table 4. Model-averaged estimates (with 95-percent confidence intervals in parentheses) of local extinction $(\hat{\bar{\varepsilon}})$ and colonization $(\hat{\bar{\gamma}})$ probabilities for barred owls in Washington and Oregon, 2015-16.

Table 5. Numbers of individual barred owls removed monthly from treatment portions of three experimental study areas, Washington and Oregon, September 2015-December 2016.

\section{Conversion Factors}

International System of Units to Inch/Pound

\begin{tabular}{|c|c|c|}
\hline Multiply & By & To obtain \\
\hline \multicolumn{3}{|c|}{ Length } \\
\hline meter (m) & 3.281 & foot $(\mathrm{ft})$ \\
\hline kilometer $(\mathrm{km})$ & 0.6214 & mile (mi) \\
\hline \multicolumn{3}{|c|}{ Area } \\
\hline hectare (ha) & 2.471 & acre \\
\hline hectare (ha) & 0.003861 & square mile $\left(\mathrm{mi}^{2}\right)$ \\
\hline square hectometer $\left(\mathrm{hm}^{2}\right)$ & 2.471 & acre \\
\hline square kilometer $\left(\mathrm{km}^{2}\right)$ & 247.1 & acre \\
\hline square kilometer $\left(\mathrm{km}^{2}\right)$ & 0.3861 & square mile $\left(\mathrm{mi}^{2}\right)$ \\
\hline
\end{tabular}




\title{
Effects of Experimental Removal of Barred Owls on Population Demography of Northern Spotted Owls in Washington and Oregon-2016 Progress Report
}

\author{
By J. David Wiens ${ }^{1}$, Katie M. Dugger², Krista E. Lewicki ${ }^{1}$, and David C. Simon ${ }^{1}$
}

\begin{abstract}
Evidence indicates that competition with invasive barred owls (Strix varia) is causing rapid declines in populations of northern spotted owls (S. occidentalis caurina), and that the long-term persistence of spotted owls may be in question without additional management intervention. A pilot study in California showed that removal of barred owls in combination with habitat conservation may be able to slow or even reverse population declines of spotted owls at local scales, but it remains unknown whether similar results can be obtained in areas with different forest conditions and a greater density of barred owls. In 2015, we implemented a before-after-control-impact (BACI) experimental design on three study areas in Oregon and Washington with at least 20 years of pre-treatment demographic data on spotted owls to determine if removal of barred owls can improve localized population trends of spotted owls. Here, we report on research accomplishments and preliminary results from the first 21 months (March 2015-December 2016) of the planned 5-year experiment.
\end{abstract}

\section{Background and Study Objectives}

Over the past century, barred owls (Strix varia) have expanded their geographic range from eastern to western North America, and their newly expanded range now completely overlaps that of the federally threatened northern spotted owl (S. occidentalis caurina). Evidence indicates that competition with invading barred owls is causing rapid declines in populations of spotted owls, and that the longterm persistence of spotted owls may be in question without additional management intervention (Wiens and others, 2014; Dugger and others, 2016). A pilot study in coastal California indicated that lethal removal of barred owls in combination with habitat conservation may be able to slow or even reverse population declines of spotted owls at local scales (Diller and others, 2016), but it remains unknown whether similar results can be obtained in larger areas with different forest conditions and where barred owls are more abundant.

\footnotetext{
${ }^{1}$ U.S. Geological Survey.

${ }^{2}$ U.S. Geological Survey and Oregon Cooperative Fish and Wildlife Research Unit, Oregon State University.
} 
In 2013, the U.S. Fish and Wildlife Service released a Final Environmental Impact Statement and Record of Decision for the experimental removal of barred owls to benefit northern spotted owls (U.S. Fish and Wildlife Service, 2013). Four study areas were identified with at least 20 years of pretreatment demographic data on spotted owls to test whether competitive interactions with barred owls cause population declines of spotted owls, and if so, whether active management of barred owls can improve population trends of spotted owls. Experimental removals were initiated in Hoopa/Willow Creek in northern California in 2013; preliminary results from that portion of the study are summarized by Franklin and others (2016).

In 2015, we initiated surveys and experimental removal of barred owls in three study areas in Washington and Oregon. The overarching goal of the study is to test the research hypothesis that the presence of barred owls causes declines in the population rate of change of spotted owls $(\lambda)$, or one of the demographic components driving declines in populations (survival, reproduction, recruitment, site occupancy dynamics; Johnson and others, 2008). Specific objectives are to:

1. Determine the effect of experimental removal of barred owls on population dynamics of spotted owls with respect to site-occupancy dynamics, reproductive output, survival, recruitment, and annual rate of population change $(\lambda \mathrm{t})$

2. Estimate pre- and post-removal differences in the probability of use by barred owls in control and treatment portions of each study area; and

3. Estimate the amount of effort and cost required to maintain low numbers of barred owls and achieve positive effects on vital rates of territorial spotted owls.

In this report, we provide an overview of our research accomplishments in Oregon and Washington during the first 21 months (March 2015-December 2016) of the planned 5-year experiment.

\section{Experimental Study Areas}

We initiated the study in three northern spotted owl demographic study areas in Washington and Oregon (fig. 1). The study areas vary in climate, vegetation composition, and topography, but all are dominated by conifer or mixed conifer-hardwood forests (Dugger and others, 2016). These areas were selected based on many considerations, including availability of pre-treatment demographic data on spotted owls, land ownership, and the need to identify the effect of barred owls on spotted owls across a broad range of forest conditions occupied by spotted owls (U.S. Fish and Wildlife Service, 2013). The study areas are comprised of mostly Federal lands, but fieldwork also occurred on adjacent State and private lands with the written permission of the landowner. A mixture of ownerships was included so that results and inferences from the study would not be limited to certain ownerships and forest conditions in the geographic range of the northern spotted owl. 


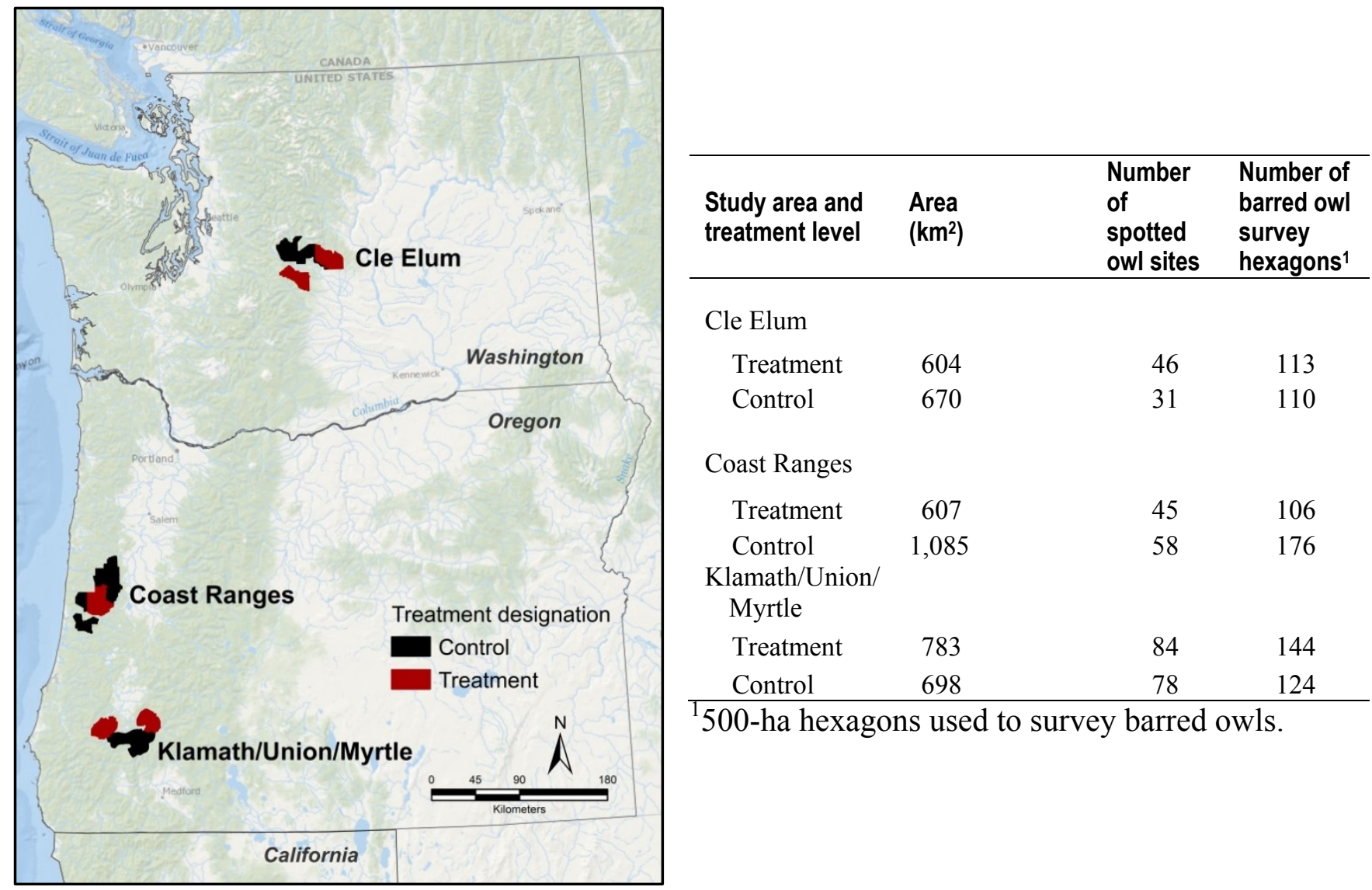

Figure 1. Control (no barred owls removed) and treatment (barred owls) portions of three study areas used to examine the effects of experimental removal of barred owls on population demography of northern spotted owls in Washington and Oregon.

\section{Methods}

\section{Owl Surveys and Demographic Monitoring}

Our study uses species-specific surveys of spotted owls and barred owls to track annual changes in populations of both species on control and treatment portions of each study area (e.g., fig. 2). Surveys of spotted owls were conducted at historically occupied territories by biologists and agencies already responsible for the long-term demographic monitoring of northern spotted owls under the Northwest Forest Plan (Lint and others, 1999, Dugger and others, 2016). Under this monitoring program, spotted owls are surveyed during the breeding season of each year (March-August) to document territory occupancy, locate owls, confirm bands of previously color-marked owls, band previously unmarked owls, and determine the number of young produced by territorial pairs (also see Lint and others, 1999). Continued demographic monitoring of spotted owls over the duration of the experiment is required to document post-treatment population trends (e.g., Dugger and others, 2016). 
We used a survey protocol developed for barred owls (U.S. Fish and Wildlife Service, 2015) in combination with the site-occupancy survey design described by Wiens and others (2011) to track annual changes in populations of barred owls on control and treatment areas. Our sampling scheme for barred owls used a standard occupancy design (MacKenzie and others, 2002, 2006) in which a grid of 500-ha hexagons were overlaid on each study area (fig. 2) and surveyed repeatedly over three periods: March 1-May 7, May 8-July 9, and July 10-September 10. Sampling periods were established to approximate mean transition dates between incubation, nestling, and fledgling-dependency breeding stages of barred owls (Wiens and others, 2011,2014). During each survey, observers used an amplified megaphone (Wildlife Technologies, Manchester, New Hampshire, and FOXPRO Inc., Lewistown, Pennsylvania) to broadcast digitally recorded calls of barred owls at established call points, distributed to provide complete coverage of the focal survey hexagon. A hexagon was considered to be used by a territorial pair of barred owls if (1) both sexes were observed within $400 \mathrm{~m}$ of each other on a single visit, (2) both sexes were observed perched together at the same time, or (3) at least 1 adult was observed with young (Wiens and others, 2011).

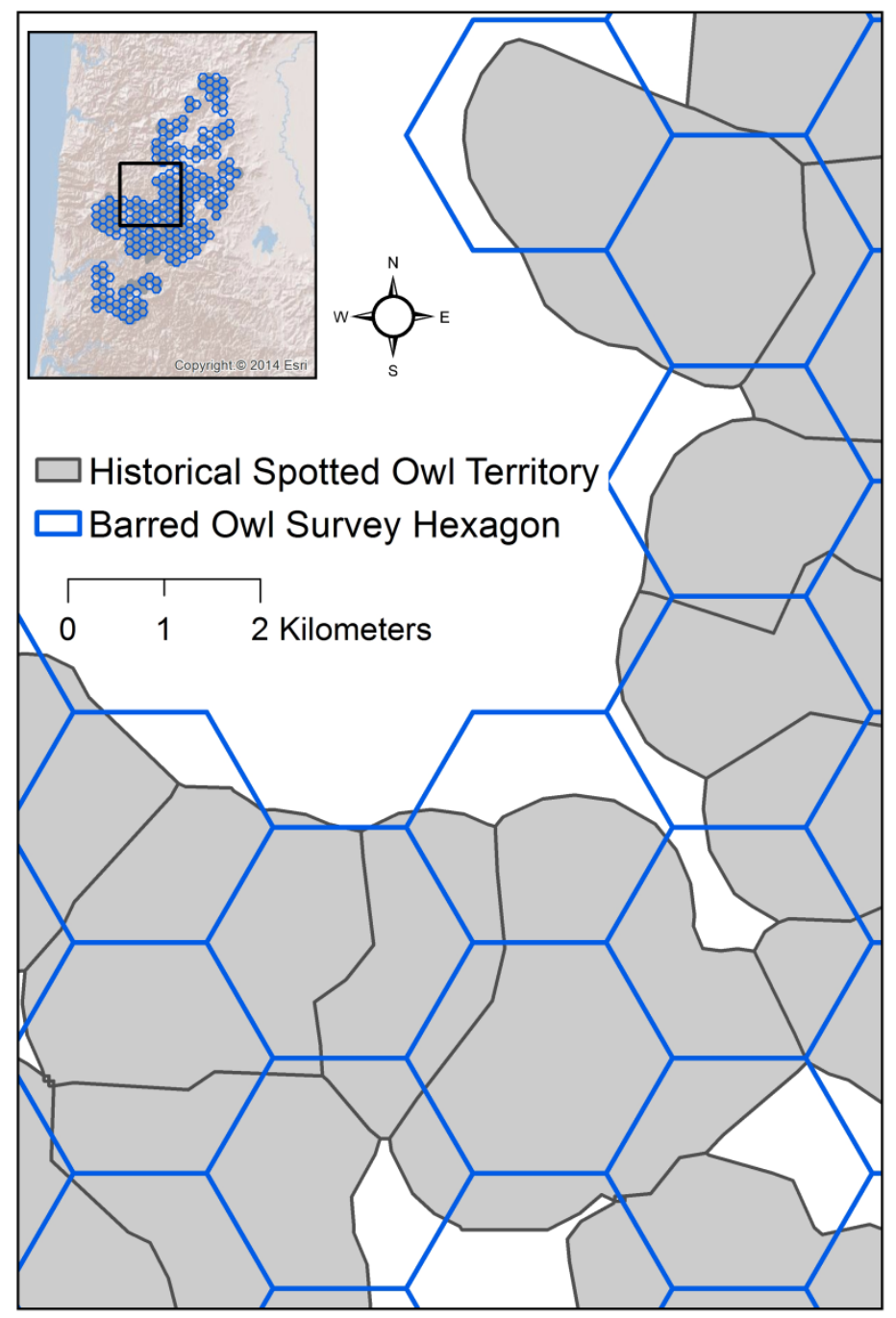

Figure 2. Example of overlap between sites surveyed for northern spotted owls (historical territories) and barred owls (500-hectare survey hexagons) in the Coast Ranges experimental study area, Oregon. 


\section{Barred Owl Removal Protocol}

We used well-established field protocols for experimental removal and scientific collection of barred owls (U.S. Fish and Wildlife Service, 2013; Diller and others, 2014, 2016). We primarily used lethal removal methods. Barred owls detected in treatment areas during surveys were lethally removed using 12-gauge shotguns with non-toxic bird shot following Diller and others (2014 2016). Our protocol for removals prohibits collection of nesting barred owls with dependent young, so removals were limited to adults or subadults not providing for dependent young, or to juvenile and immature birds independent of parental care (U.S. Fish and Wildlife Service, 2013). As a consequence of uncertainties associated with determining nesting status of barred owls during the first year of the study, removals occurred primarily during the nonbreeding season (approximately September-March). We anticipated frequent colonization of barred owls into areas where barred owls were removed (Yackulic and others, 2014; Diller and others, 2014, 2016), so we conducted regular follow-up visits to determine changes in occupancy by barred owls at these sites and conducted additional removals as needed. Removal of barred owls by USGS-certified personnel was authorized under Federal and State permits. All survey and removal methods, and field personnel engaged in these activities, were approved by the Institutional Animal Care and Use Committee (IACUC) at Oregon State University.

\section{Data Summary and Analysis}

We used survey data from spotted owls to summarize occupancy and reproductive status on control versus treatment portions of each study area. We used Theissen polygons to delineate historical territories used by spotted owls and assess occupancy status by individually marked owls (Dugger and others, 2016). A preliminary analysis of the demographic response of spotted owls to experimental removals is scheduled to occur after a full 3 years of removals have been completed on each study area (see section, "Schedule to Completion").

For barred owls, we summarized survey detections of territorial pairs obtained during surveys completed in 2015 and 2016 using (1) the mean center of repeated survey detections of a territorial pair, or (2) the location of adults with fledged young (Wiens and others, 2011). We used these data to characterize numbers of territorial pairs of barred owls detected in control versus treatment portions of each study area, but relied on estimation methods described in the sections that follow to estimate annual changes in the size of the treatment effect (i.e., the annual rate of change in use of treatment versus control area by barred owls). 


\section{Probability of Barred Owl Use in Control and Treatment Areas}

\section{Cle Elum and Coast Ranges Study Areas, 2015-16}

We used multi-season (robust-design) occupancy models in program MARK (White and Burnham, 1999) to estimate the probability of use for barred owls in the Cle Elum and Coast Ranges study areas before (2015) and after (2016) removals. Actual territory boundaries of barred owls may overlap more than $(>) 1$ survey hexagon in our study, so we interpreted the occupancy parameter $(\psi)$ as the probability of greater than or equal to $(\geq) 1$ pair of barred owls using a given hexagon during the breeding season (MacKenzie and others, 2006). We used detection histories from breeding season surveys to estimate the probability of use in the first year $(\psi)$, the probability that a previously used site was not used in the subsequent year (extinction; $\varepsilon$ ), the probability that a vacant site was used in the subsequent year (colonization; $\gamma$ ), and the probability of detection $(p)$. A sample site in our study was a 500 -ha hexagon used for surveys, and for this analysis we focused inferences on detections of $\geq 1$ pair of barred owls because our primary interest was in examining effects of removals on the breeding segment of the population.

The goal of our analysis was to assess evidence for pre- and post-treatment difference in $\psi, \varepsilon$, and $\gamma$ between control and treatment areas. We did this using a two-step approach that compared support for candidate models with and without the effects of treatment (area) and time (year, survey period). We first considered models where detection probabilities $(p)$ were held constant, or varied with survey occasion or between years. Next, we retained the best-supported model of detection probability and proceeded to model initial occupancy, colonization, and extinction parameters with and without treatment (area) effects. We used information theoretic methods (Burnham and Anderson, 2002) to select the best models at each step of our analysis. We evaluated the degree to which $95 \%$ confidence intervals of regression coefficients $(\beta)$ overlapped zero to determine strength of treatment and time effects. We calculated model-averaged estimates of the annual proportion of sites used by barred owls $\left(\psi_{t}\right)$, and the annual rate of change in the probability of use $\left(\lambda_{t}\right)$ following MacKenzie and others (2002), which were estimated from annual estimates of $\varepsilon$ and $\gamma$ as derived parameters in Program MARK. Note that estimates of the annual rate of change in occupancy derived from presence/absence data $\left(\lambda_{t}\right)$ are interpreted the same as estimates of population change derived from more intensive mark-recapture studies (Conner and others, 2016).

Klamath/Union/Myrtle Study Area, 2016

We had incomplete survey data on barred owls in 2015 at Klamath/Union/Myrtle, so we limited our analysis of barred owl use to the 2016 breeding season, prior to when removals were initiated in this study area. Here, we used single-season site occupancy models in program MARK to estimate the probability of detecting $\geq 1$ territorial pairs of barred owls at survey hexagon $i$ during survey occasion $t$, given presence $(p)$, and the probability of use by a pair of barred owls ( $\psi$; MacKenzie and others, 2003, 2006). We considered models where detection probabilities $(p)$ were held constant, or varied with survey occasion $(t)$, and assessed evidence for differences in $\psi$ and $p$ between control and treatment sites by comparing support for models with and without treatment effects (also see Wiens and others, 2016). 


\section{Preliminary Results, March 2015-December 2016}

We completed surveys of barred owls on the treatment and control portions of the Cle Elum and Coast Ranges study areas during March-September 2015 and 2016, and conducted removals of barred owls on treatment portions of these study areas during September 2015-April 2016, and August 2016December 2016; (fig. 3). Surveys of barred owls were initiated on the Klamath/Union/Myrtle study area in 2015, but were incomplete because of delays in securing land access permits from private landowners. Consequently, pre-treatment surveys were not completed on the Klamath/Union/Myrtle study area until 2016, and experimental removals were not initiated until October 2016 (fig. 3). Removal activities on the Cle Elum and Coast Ranges study areas are expected to continue through 2019, and through 2020 on the Klamath/Union/Myrtle area (see section, "Schedule to Completion").

There were brief periods where surveys of barred owls and removals were being conducted simultaneously, especially in early spring 2016 (fig. 3). This required that removal and survey crews coordinate closely so that breeding season surveys were not initiated at sites until removals were completed. Similarly, removals were not initiated at sites in autumn until those sites were completed for the 2016 survey season. Our removal efforts during periods of overlap were focused on sites where (1) spotted owls had been detected during the previous breeding season, or (2) barred owls were observed rapidly recolonizing after established residents were removed during preceding field visits.

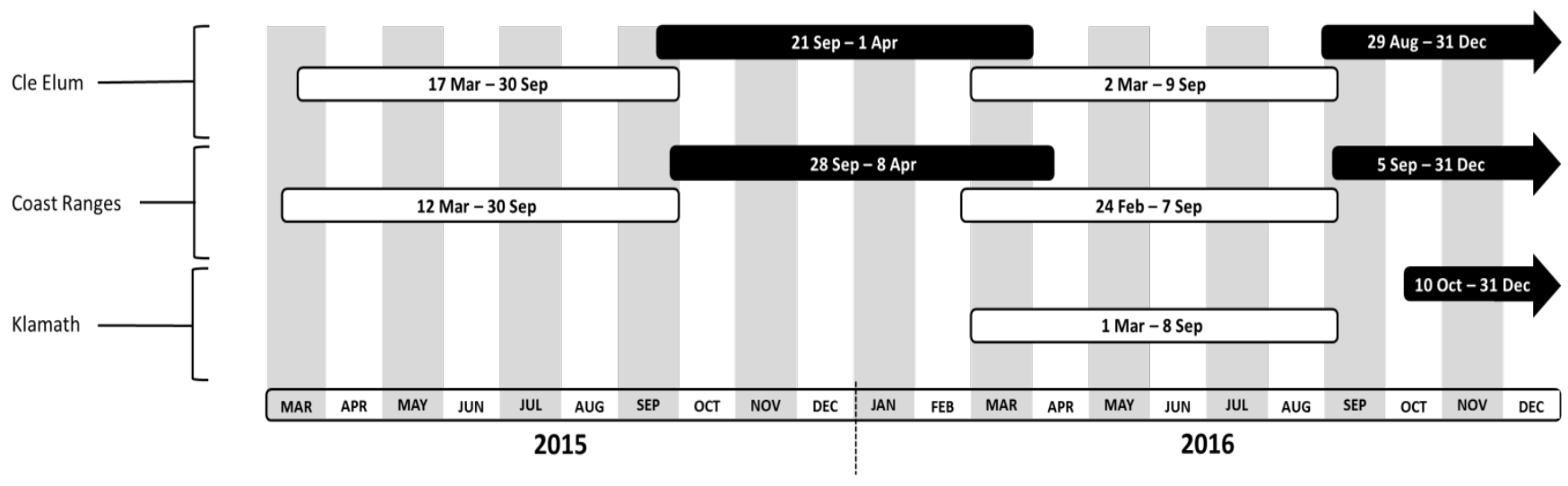

Figure 3. Timeline of barred owl survey (white) and removal (black) efforts in the Cle Elum, Coast Ranges, and Klamath/Union/Myrtle experimental study areas, Washington and Oregon, 2015-16. Arrows indicate ongoing activities into the following year. 


\section{Owl Surveys and Demographic Monitoring}

\section{Spotted Owls}

During 2015-16, surveys of spotted owls were completed at 342 territories historically occupied by spotted owls on the Cle Elum, Coast Ranges, and Klamath/Union/Myrtle study areas (table 1, appendix A). At least one spotted owl was detected at $70(20 \%)$ of 342 territories in 2016, whereas territorial pairs of spotted owls were detected at 44 (13\%) of historically occupied territories. Estimates of the proportion of historical territories with detections of spotted owls tended to be greater in control versus treatment portions of both study areas, but sample sizes were small and these estimates do not account for imperfect detection probability. Estimates reported herein for spotted owls are specific to the experimental (control/treatment) portion of each study area, so may vary from those reported for broader long-term demographic study areas monitored under the Northern Spotted Owl Northwest Forest Plan Monitoring Program (for details, see https://reo.gov/monitoring/reports/northern-spottedowl-reports-publications.shtml).

Table 1. Northern spotted owl survey effort, detections at historically occupied territories, and observed reproduction on treatment (barred owls removed) versus control (barred owls not removed) portions of three experimental study areas, Washington and Oregon, 2015-16.

[Symbols: $\geq$, greater than or equal to; \%, percent]

\begin{tabular}{|c|c|c|c|c|c|c|c|}
\hline \multirow{2}{*}{$\begin{array}{l}\text { Experimental } \\
\text { study area }\end{array}$} & \multirow{2}{*}{$\begin{array}{l}\text { Historical } \\
\text { spotted } \\
\text { owl } \\
\text { territories } \\
\text { surveyed }\end{array}$} & \multicolumn{2}{|c|}{$\begin{array}{l}\text { Number of territories } \\
\text { with } \geq 1 \text { spotted owl } \\
\text { ( } \% \text { of sites surveyed) }\end{array}$} & \multicolumn{2}{|c|}{$\begin{array}{l}\text { Number of territories } \\
\text { with spotted owl pair } \\
\text { (\% of sites surveyed) }\end{array}$} & \multicolumn{2}{|c|}{$\begin{array}{l}\text { Number of territories } \\
\text { with } \geq 1 \text { young fledged } \\
\text { ( } \% \text { of sites with pairs) }\end{array}$} \\
\hline & & 2015 & 2016 & 2015 & 2016 & 2015 & 2016 \\
\hline \multicolumn{8}{|l|}{ Cle Elum, Washington } \\
\hline Treatment & 46 & $4(9 \%)$ & $6(13 \%)$ & $2(4 \%)$ & $2(4 \%)$ & $1(50 \%)$ & $2(100 \%)$ \\
\hline Control & 31 & $6(19 \%)$ & $6(19 \%)$ & $5(16 \%)$ & $2(6 \%)$ & $2(40 \%)$ & 0 \\
\hline \multicolumn{8}{|c|}{ Coast Ranges, Oregon ${ }^{1}$} \\
\hline Treatment & 45 & $7(16 \%)$ & $5(11 \%)$ & $3(7 \%)$ & $4(11 \%)$ & 0 & $1(25 \%)$ \\
\hline Control & 58 & $17(29 \%)$ & $14(24 \%)$ & $11(19 \%)$ & $9(16 \%)$ & $3(27 \%)$ & 0 \\
\hline \multicolumn{8}{|c|}{$\begin{array}{l}\text { Klamath/Union/Myrtle, } \\
\text { Oregon }^{2}\end{array}$} \\
\hline Treatment & 84 & & $18(21 \%)$ & & $12(14 \%)$ & & $1(8 \%)$ \\
\hline Control & 78 & & $21(27 \%)$ & & $15(19 \%)$ & & $1(7 \%)$ \\
\hline
\end{tabular}

${ }^{1}$ Two pairs of spotted owls were detected on one historical spotted owl territory in the treatment area of the Coast Ranges study area in 2016 (equals 5 pairs in the treatment area in 2016; 1 of which successfully fledged young).

${ }^{2}$ The study was not initiated on the Klamath/Union/Myrtle study areas until 2016. 


\section{Barred Owls}

We completed surveys of barred owls at 500 sites (500-ha hexagons) in two of the three study areas in 2015, and at 773 sites in all three study areas combined in 2016. The percentage of survey hexagons with $\geq 1$ barred owl, or $\geq 1$ pair of barred owls, detected in treatment areas was similar or lower following the first year of removals on the Cle Elum and Coast Ranges study areas (table 2). In 2015, we detected $\geq 1$ barred owl pair in $58 \%$ and $78 \%$ of treatment sites surveyed in Cle Elum and Coast Ranges, respectively, whereas we detected $\geq 1$ barred owl pairs in only $27 \%$ and $68 \%$ of these sites, respectively, in 2016. The percentage of sites in the Cle Elum control area where $\geq 1$ pair of barred owl were detected decreased between 2015 (55\%) and 2016 (45\%), but this difference (10\%) was less pronounced than what we observed in the treatment area $(31 \%$; table 2$)$. In the Coast Ranges study area, the percentage of sites with $\geq 1$ barred owl pair detected increased by $7 \%$ between 2015 (68\%) and 2016 $(75 \%)$, but decreased by $10 \%$ in the treatment area. The percentage of hexagons surveyed where barred owls (individuals or pairs) were detected in Klamath/Union/Myrtle during pre-treatment surveys was 20-30\% lower than in the Coast Ranges study area.

In the Cle Elum study area, the mean number of individual barred owls detected per survey site (i.e., pairs plus apparent single birds; fig. 4a) and the mean number of pairs detected (fig. 4b) declined in the treatment area from 2015 to 2016. In the Coast Ranges study area, the mean number of individuals and pairs of barred owls detected per site in the treatment area declined, but increased in the control areas (figs. $4 \mathrm{a}, 4 \mathrm{~b})$.

Table 2. Barred owl survey and detections at sites (500-hectare survey hexagons) on treatment (barred owls removed) versus control (barred owls not removed) portions of three experimental study areas, Washington and Oregon, 2015-16.

[Symbols: $\geq$, greater than or equal to; \%, percent]

\begin{tabular}{|c|c|c|c|c|c|}
\hline \multirow[t]{2}{*}{$\begin{array}{l}\text { Experimental } \\
\text { study area }\end{array}$} & \multirow[t]{2}{*}{$\begin{array}{l}\text { Number of } 500- \\
\text { hectare hexagons } \\
\text { surveyed }\end{array}$} & \multicolumn{2}{|c|}{$\begin{array}{c}\text { Number of hexagons with } \geq 1 \\
\text { individual barred owls } \\
\text { detected at least once } \\
\text { (\% of sites surveyed) }\end{array}$} & \multicolumn{2}{|c|}{$\begin{array}{c}\text { Number of hexagons with } \geq 1 \\
\text { pair of barred owls } \\
\text { detected at least once } \\
\text { (\% of sites surveyed) } \\
\end{array}$} \\
\hline & & 2015 & 2016 & 2015 & 2016 \\
\hline \multicolumn{6}{|l|}{ Cle Elum, Washington } \\
\hline Treatment & 113 & $90(80 \%)$ & $76(67 \%)$ & $66(58 \%)$ & $31(27 \%)$ \\
\hline Control & 110 & $83(75 \%)$ & $86(78 \%)$ & $61(55 \%)$ & $49(45 \%)$ \\
\hline \multicolumn{6}{|l|}{ Coast Ranges, Oregon } \\
\hline Treatment & 106 & $97(92 \%)$ & $101(95 \%)$ & $83(78 \%)$ & $72(68 \%)$ \\
\hline Control & 171 & $148(87 \%)$ & $159(90 \%)$ & $117(68 \%)$ & $132(75 \%)$ \\
\hline \multicolumn{6}{|c|}{ Klamath/Union/Myrtle, Oregon ${ }^{1}$} \\
\hline Treatment & 143 & & $111(78 \%)$ & & $68(48 \%)$ \\
\hline Control & 125 & & $82(66 \%)$ & & $48(38 \%)$ \\
\hline
\end{tabular}

${ }^{1}$ Incomplete survey data in 2015; we show pre-treatment data from 2016 only. 
a)

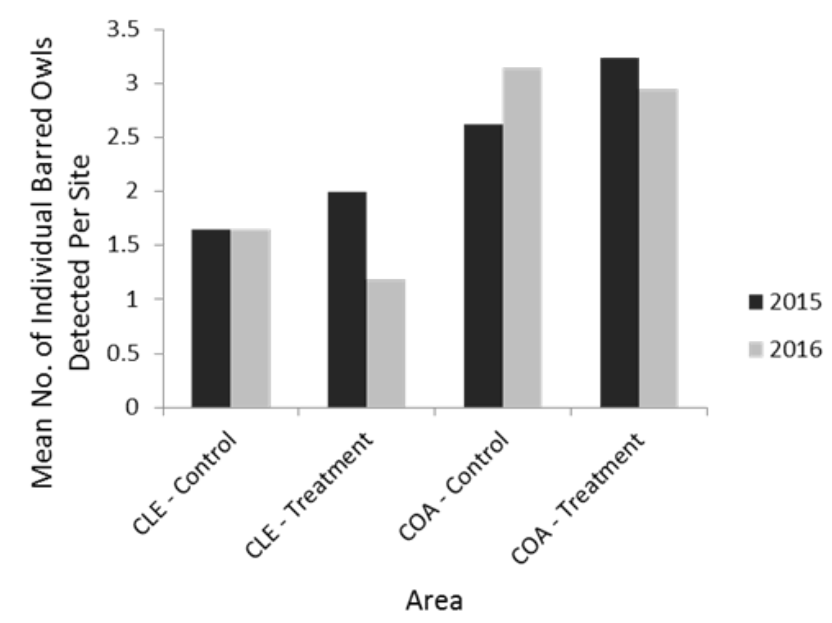

b)

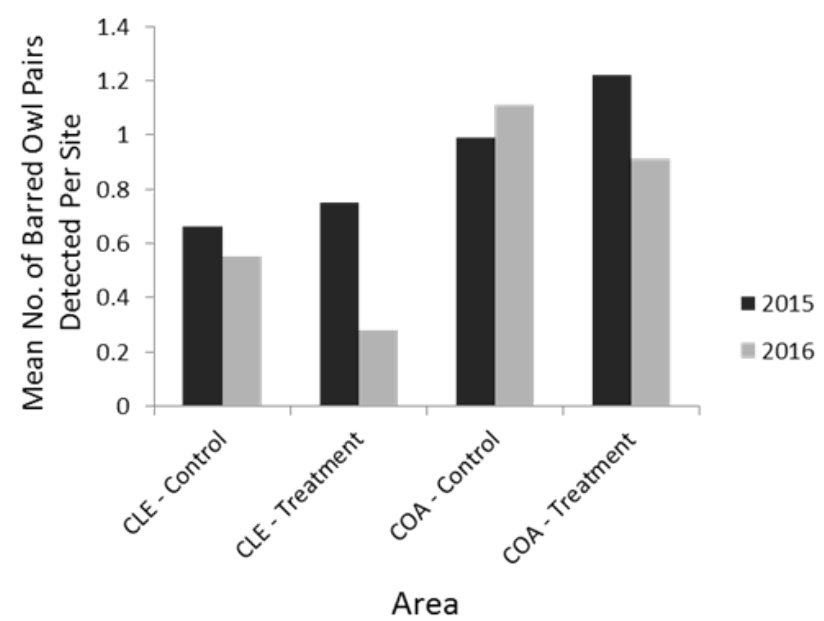

Figure 4. Mean number of barred owl (a) individuals and (b) pairs detected per survey site (500-hectare hexagon) in control and treatment areas of the Cle Elum (CLE) and Coast Ranges (COA) study areas, Washington and Oregon, 2015-16.

\section{Probability of Barred Owl Use in Control and Treatment Areas}

In the Cle Elum study area, we estimated a $24-25 \%$ decline in the probability of use by territorial pairs of barred owls on control and treatment areas between 2015 and 2016 (table 3), and there was weak support for a treatment effect of removals on extinction and colonization parameters (table 4; appendix B). Model-averaged estimates of the annual rate of change in the probability of use ( $\lambda$ ) were $<1.0$ in control and treatment areas, and $95 \%$ confidence intervals did not overlap zero (table 3), indicating a significant decline in use of the entire study area by pairs of barred owls between 2015 and 2016.

In the Oregon Coast Ranges study area, model-averaged estimates of the probability of use were 0.920 in the control area during both years, but declined to 0.792 in the treatment area following removals in 2016 (table 3). Extinction probability was about 16\% greater in the treatment area relative to the control area (table 4), and the regression coefficient for a treatment effect on this parameter did not overlap zero ( $\hat{\beta}=-0.75,95 \% \mathrm{CI}=-1.05$ to -0.46 ), indicating a significant effect of removals on extinction probability. Model-averaged estimates of the annual rate of change in probability of use were $<1.0$ in the treatment area, and the $95 \%$ confidence intervals did not overlap zero, indicating a significant decline between years in use of the treatment area, but not on the control area, by pairs of barred owls (table 3, appendix C).

In the Klamath/Union/Myrtle study area, model-averaged estimates of the probability of use were slightly greater on the treatment relative to the control area (table 3), but models that included a treatment effect on the probability of use were not strongly supported by the data (appendix D).

The estimated probability of detecting $\geq 1$ pairs of barred owls that were present during a single survey occasion $(p)$ ranged from 0.43 (standard error $[\mathrm{SE}]=0.04)$ to $0.68(\mathrm{SE}=0.04)$ across all three study areas. Models that accounted for time-dependency among survey occasions and years in detection generally received greater support than models that did not (appendixes B, C, D). We found no support for differences in $p$ between control and treatment areas on Coast Ranges or Klamath/Union/Myrtle, but we did find evidence of an area effect on $p$ in Cle Elum (probability of detection declined to 0.28 [SE $=$ $0.05]$ in 2016). 
Table 3. Model-averaged estimates, with standard errors (SE) and lower (LCl) and upper (UCI) 95-percent confidence intervals, of the probability of use by territorial pairs of barred owls $(\hat{\bar{\psi}})$, and annual rate of change in the probability of use $(\hat{\bar{\lambda}})$, in two experimenl study areas, Oregon and Washington, 2015-16.

[Experimental removals were implemented in Cle Elum and Coast Ranges in October 2015; we show only single-season, pre-treatment (2016) estimates for Klamath/Uon/Myrtle]

\begin{tabular}{|c|c|c|c|c|c|c|c|c|}
\hline \multirow{2}{*}{$\begin{array}{l}\text { Study area and model } \\
\text { parameter }\end{array}$} & \multicolumn{4}{|c|}{2015} & \multicolumn{4}{|c|}{2016} \\
\hline & Estimate & SE & $\mathrm{LCl}$ & $\mathrm{UCl}$ & Estimate & SE & $\mathrm{LCl}$ & $\mathrm{UCl}$ \\
\hline \multicolumn{9}{|l|}{ Cle Elum, Washington } \\
\hline$\hat{\bar{\psi}}$ (control) & 0.722 & 0.050 & 0.615 & 0.809 & 0.521 & 0.055 & 0.414 & 0.626 \\
\hline$\hat{\bar{\psi}} \cdot($ treatment $)$ & 0.726 & 0.050 & 0.617 & 0.813 & 0.505 & 0.090 & 0.337 & 0.673 \\
\hline$\hat{\bar{\lambda}}$ (control) & & & & & 0.721 & 0.080 & 0.542 & 0.849 \\
\hline$\hat{\bar{\lambda}}$ (treatment) & & & & & 0.696 & 0.128 & 0.411 & 0.883 \\
\hline \multicolumn{9}{|l|}{ Coast Ranges, Oregon } \\
\hline$\hat{\bar{\psi}}$ (control) & 0.920 & 0.039 & 0.805 & 0.969 & 0.931 & 0.035 & 0.821 & 0.975 \\
\hline$\hat{\bar{\psi}}$ (treatment) & 0.938 & 0.026 & 0.864 & 0.973 & 0.792 & 0.058 & 0.657 & 0.883 \\
\hline$\hat{\bar{\lambda}}$ (control) & & & & & 1.021 & 0.043 & 0.937 & 1.104 \\
\hline$\overline{\hat{\lambda}}$ (treatment) & & & & & 0.850 & 0.066 & 0.674 & 0.940 \\
\hline \multicolumn{9}{|l|}{$\begin{array}{l}\text { Klamath/Union/Myrtle, } \\
\text { Oregon }\end{array}$} \\
\hline$\hat{\bar{\psi}}$ (control) & & & & & 0.563 & 0.074 & 0.416 & 0.699 \\
\hline$\hat{\bar{\psi}}$ (treatment) & & & & & 0.646 & 0.074 & 0.492 & 0.774 \\
\hline
\end{tabular}

Table 4. Model-averaged estimates (with 95-percent confidence intervals in parentheses) of local extinction $(\hat{\bar{\varepsilon}})$ and colonization $(\hat{\bar{\gamma}})$ probabilities for barred owls in Washington and Oregon, 2015-16.

\begin{tabular}{cccccc}
\hline \multirow{2}{*}{ Study area } & \multicolumn{2}{c}{ Local extinction $(\hat{\bar{\varepsilon}})$} & & \multicolumn{2}{c}{ Local colonization $(\hat{\bar{\gamma}})$} \\
\cline { 2 - 3 } \cline { 5 - 6 } & Control & Treatment & & Control & Treatment \\
\hline $\begin{array}{c}\text { Cle Elum, } \\
\text { Washington }\end{array}$ & $0.293(0.172-0.453)$ & $0.345(0.161-0.592)$ & & $0.036(0.001-0.892)$ & $0.110(0.006-0.701)$ \\
$\begin{array}{c}\text { Coast Ranges, } \\
\text { Oregon }\end{array}$ & $0.002(0.000-0.036)$ & $0.158(0.070-0.316)$ & & $0.253(0.009-0.724)$ & $0.101(0.000-0.717)$ \\
\hline
\end{tabular}




\section{Barred Owl Removals}

From September 21, 2015, to December 28, 2016, we removed 643 individual barred owls from treatment areas in Washington and Oregon, including 286 females, 317 males, and 40 individuals of undetermined sex (table 5). This represented a minimum of 168 territorial pairs of barred owls (i.e., cases where a territorial male and female were both collected within $150 \mathrm{~m}$ of each other on the same removal occasion). We used lethal removal methods for all barred owls, with the exception of one adult male captured in the Oregon Coast Ranges and transported to the High Desert Museum in Bend, Oregon. During the first 11 months of removals, the mean number of barred owls collected in historical territories of spotted owls (i.e., Thiessen polygons) in treatment areas was $3.0 \pm 2.7$ (standard deviation [SD]) in Cle Elum (range $=0-12$ owls), and 6.7 $\pm 4.4(\mathrm{SD})$ in the Oregon Coast Ranges (range $=0-20$ owls).

Table 5. Numbers of individual barred owls removed monthly from treatment portions of three experimental study areas, Washington and Oregon, September 2015-December 2016.

[Months in which removals were not conducted are indicated with shaded areas]

\begin{tabular}{llcccr}
\hline Year and month & $\begin{array}{c}\text { Cle Elum, } \\
\text { Washington }\end{array}$ & $\begin{array}{c}\text { Coast Ranges, } \\
\text { Oregon }\end{array}$ & $\begin{array}{c}\text { Klamath/Union/Myrtle, } \\
\text { Oregon }\end{array}$ & $\begin{array}{c}\text { Washington and Oregon total } \\
\text { (Females, males, undetermined sex) }\end{array}$ \\
\hline 2015 & September & 27 & 15 & & $42(20,22,0)$ \\
& October & 74 & $84^{1}$ & $158(73,80,5)$ \\
& November & 5 & 43 & $48(20,27,1)$ \\
& December & 1 & 5 & & $6(3,2,1)$ \\
2016 & 0 & 7 & & $7(4,3,0)$ \\
& January & 83 & 54 & $41(15,23,3)$ \\
& February & 3 & & $64(24,27,13)$ \\
& March & 10 & No breeding season removals in 2016 & $3(0,1,2)$ \\
& April & & & & $13(6,7,0)$ \\
& & 81 & 34 & $67(30,33,4)$ \\
& August & 13 & 8 & 32 & $70(33,35,2)$ \\
& September & 21 & 27 & 15 & $22(11,10,1)$ \\
& October & 25 & 7 & $\mathbf{8 1}$ & $\mathbf{6 4 3}(\mathbf{2 8 6 , 3 1 7 , 4 0 )}$ \\
\hline
\end{tabular}

${ }^{1}$ Includes one non-lethal removal of a male barred owl (live-capture provided to the High Desert Museum, Bend, Oregon). 
Field crews fired 660 shots from 12-gauge shotguns to lethally remove 642 barred owls from experimental treatment areas (first-shot success rate $=97.3 \%$ ). We had 16 cases where the first shot was not lethal so a second shot was immediately taken, and 4 cases where a shot apparently missed the bird. Twenty-nine (4.5\%) of 642 barred owls required euthanasia to ensure rapid death following a single, apparently non-lethal shot. Euthanasia was administered immediately following a non-lethal shot using a Ballista penetrating bolt device (Bunny Rancher, Frankfort, Maine) that was approved for use in this study by the Institutional Animal Care and Use Committee at Oregon State University. We successfully recovered 637 carcasses of barred owls following lethal removal; we were unable to recover the carcasses of 5 owls that got stuck high in a tree or had fallen into areas unsafe for access. Owl carcasses are being distributed to museums and universities to be prepared as scientific specimens for future research and educational opportunities.

At least one spotted owl was detected on 24 (2.1\%) of 1,108 field visits to remove barred owls. In cases where spotted owls and barred owls were detected simultaneously, observers only attempted to remove barred owls if the spotted owl could be heard vocalizing $>150 \mathrm{~m}$ in the opposite direction of the removal location, or if a second observer was available to watch the spotted owl while the barred owl was collected. There were no known cases where a non-target species was mistakenly collected or injured.

\section{Removal Success Rate}

Seven biologists made 1,108 field visits to collect $643(60 \%)$ of 1,072 individual barred owls detected in treatment areas of the three experimental study areas. Excluding removal field visits where no barred owls were detected $(n=534)$, the overall mean per-visit success rate (i.e., number barred owls removed per visit $\div$ number barred owls detected) was greater in Cle Elum $(0.74 \pm 0.38$ [SD], $n=155$ visits $)$ as compared to the Coast Ranges $(0.58 \pm 0.41, n=285$ visits; fig. 5$)$. During the first three months of removals in Klamath/Union/Myrtle (October-December 2016), the mean per-visit success rate was 0.49 ( $\mathrm{SD}=0.44, n=91$ visits). The removal success rate tended to be greater at Cle Elum relative to the Oregon study areas partly because of the drier, more open forest conditions there that provide field crews with more opportunities to access, locate, and collect vocalizing barred owls.
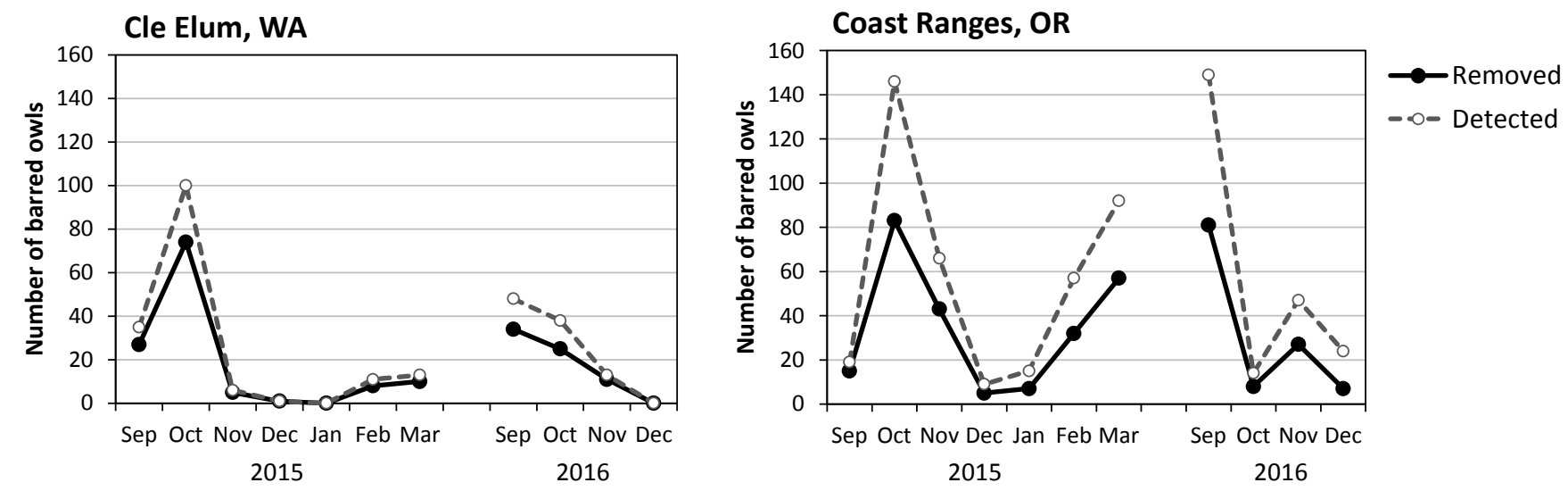

Figure 5. Total numbers of barred owls detected versus removed during field visits to the Cle Elum and Coast Ranges experimental study areas, Washington and Oregon September 2015-December 2016. No removals were conducted during the 2016 breeding season (April-August). 


\section{Age of Recolonizing Barred Owls}

We attempted to determine the age of all barred owls collected as either adults ( $\geq 3$ years old) or subadults (1-2 years old) based on molt and plumage characteristics observed under ultraviolet light (Weidensaul and others, 2011). Determining the age of barred owls is an important aspect of the study because an increase in the proportion of pre-adults in the breeding component of large populations of birds of prey can serve as a strong indicator of an imminent decline in the breeding population (Hunt 1998; Penteriani and others, 2011). We observed a clear transition in age-class of barred owls collected during the first 16 months of removals, with a substantially greater proportion of territorial subadults collected at sites where established resident adult pairs had been removed in previous months (fig. 6). The numbers of subadult barred owls were especially high in the second season of removals (Cle Elum and Coast Ranges only), immediately followed the 2016 breeding season. This pattern would be expected if younger first- and second-year birds were available in treatment landscapes to quickly identify and fill breeding vacancies created by experimental removals.

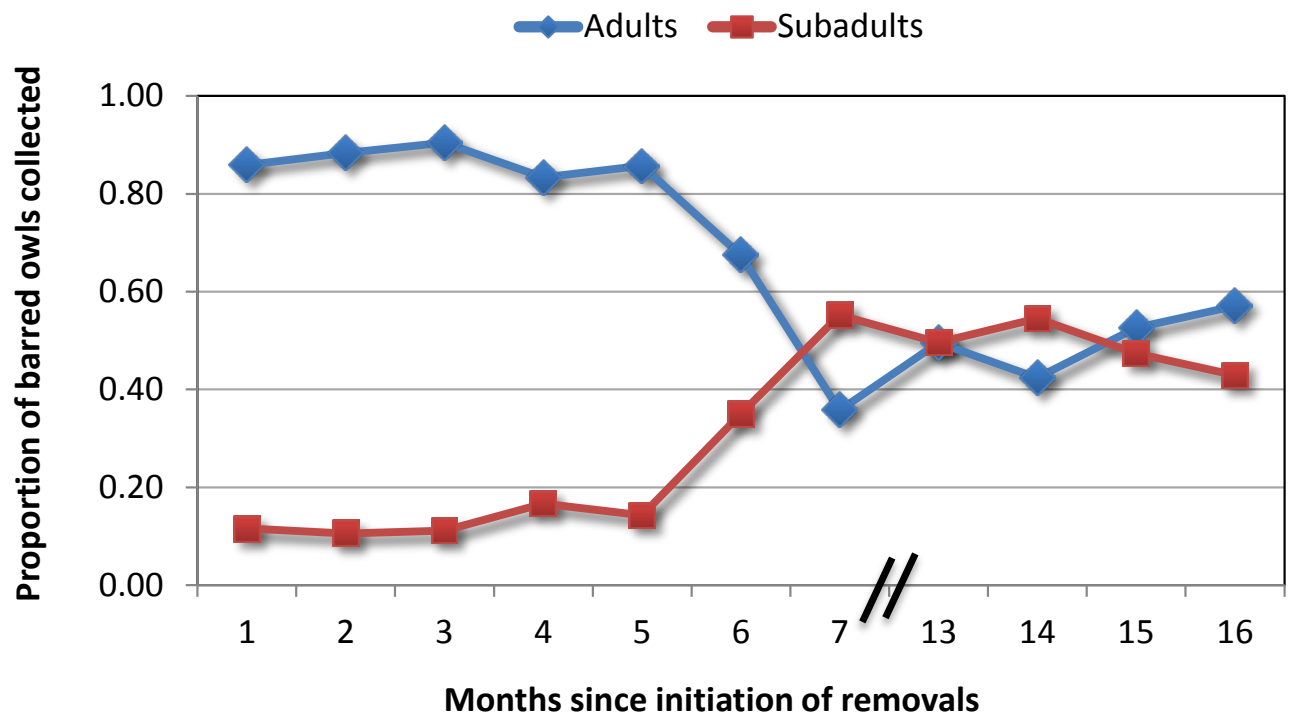

Figure 6. Change in the proportion of barred owls collected that were either adults (3 years or older) or subadults (1-2 years old) during the first 16 months after removals were initiated on three study areas, Washington and Oregon, 2015-16. Note that no removals were conducted during the 2016 breeding season (months 8-12 since initiation of removals, represented with black lines).

\section{Breeding Season Removals, 2017}

As specified by U.S. Fish and Wildlife Service (2013), removal of non-nesting adults or subadults may occur during the breeding season if a credible approach is developed to determine nonnesting status of barred owls with high confidence. During the course of removal activities, we determined that certain sites have a higher rate of recolonization by barred owls than others, and that the frequency and extent at which barred owls are removed from these sites can provide strong evidence that the birds are not nesting. Thus, based on review and approval by the U.S. Fish and Wildlife Service, we will begin conducting localized removals of barred owls during the breeding season at sites where (1) spotted owls had been detected during the previous breeding season, or (2) rapid (2-3 week) recolonization by barred owls has been observed following removals of established residents during preceding field visits conducted in autumn and winter. 


\section{Associated Research Activities}

\section{Specimen Deposition}

In 2016, we began distributing barred owl carcasses (all collected as scientific specimens) to various museums and educational facilities for use in future research. As of December 31, 2016, the California Academy of Sciences, Burke Museum, Oregon Department of Forestry, and Liberty Wildlife Feather Repository received a combined total of 64 barred owl specimens. An additional three specimens were used to create realistic mechanical decoys for use in future mark-recapture studies of barred owls and other raptor species.

\section{Assessment of Barred Owl Rodenticide Exposure}

We have been taking fluid and tissue samples from barred owl carcasses for the purposes of genetic, blood parasite, and toxicology studies. We also are collecting the livers and digestive tracts from a subset of the barred owl carcasses. We plan to analyze the livers in combination with the toxicology blood samples.

\section{Barred Owl Diets and Effects on Other Species}

Rapid increases in the distribution and abundance of an apex predator like the barred owl can have substantial effects on native prey species or other competing native predators (Holm and others, 2016). The barred owl removal experiment provides a unique opportunity to determine the influence of barred owls on other sensitive species, and to test hypotheses broadly relevant to community ecology and the role of top-down predation on structuring biodiversity and ecosystem processes. For his dissertation research, a Ph.D. candidate at the Department of Fisheries and Wildlife at Oregon State University will be examining the contents of the digestive tracts of barred owls collected in the experiment to determine diets, with the goal of using the established experimental framework to examine the effects of barred owl removal on abundance and distribution of sensitive prey species identified in diets of barred owls collected during removal experiments.

\section{Demographic Simulation Models of Species Interactions to Guide Barred Owl Removal Strategies}

This study uses a recently developed two-species computer simulation model of competitive interactions between northern spotted owls and barred owls to explore the efficacy of potential barred owl management strategies intended to promote viability of spotted owls. The simulation model can be used to examine the cost and potential benefits of future barred owl removal efforts to management goals for spotted owls. For her thesis research, an M.S. candidate in the Department of Geography at Oregon State University has initiated simulation experiments to explore the trade-offs that emerge from altering the spatial and temporal distribution of a fixed overall removal effort.

\section{Development of a Standardized Aging Method for Barred Owls}

We recently have developed a standardized method for distinguishing barred owl adults from first- and second-year subadults using the molting patterns on flight feathers (e.g., Weidensaul and others, 2011). We are continuing to document molting patterns on each bird collected; publication on our methods will be forthcoming. 


\section{Summary}

- During 2015 and 2016, we completed pre- and post-treatment surveys of barred owls on the Cle Elum, Washington, and Coast Ranges, Oregon, study areas, and pre-treatment surveys of barred owls on the Klamath/Union/Myrtle study area, Oregon. Removals of barred owls were conducted on the Cle Elum treatment areas during September 2015-April 2016, in the Coast Ranges treatment area during September 2016-December 2016, and during October-December 2016 in the Klamath/Union/Myrtle treatment areas.

- Long-term monitoring of spotted owls was continued at 342 historically occupied breeding territories on the experimental portions of the Cle Elum, Coast Ranges, and Klamath/Union/Myrtle demographic study areas. At least one spotted owl was detected at 70 $(20 \%)$ of 342 territories surveyed, whereas territorial pairs of spotted owls were detected at 44 $(13 \%)$ territories.

- Only 11 pairs of spotted owls successfully fledged young across all study areas in 2015 and 2016 combined.

- Field crews removed a total of 643 barred owls from three experimental study areas in Washington and Oregon combined, including 286 females, 317 males, and 40 birds of undetermined sex.

- Perhaps because of differences among study areas in forest conditions, mean per-visit success rate of removals (i.e., number barred owls removed $\div$ number detected) tended to be greater in the Cle Elum study area (0.74) relative to the Coast Ranges ( 0.58$)$ or Klamath/Union/Myrtle study areas (0.49).

- In the Cle Elum study area, we estimated a $24-25 \%$ decline in the probability of use by territorial pairs of barred owls on both control and treatment areas between 2015 and 2016. Estimates of the annual rate of change in use $\left(\lambda_{t}\right)$ were $1<1.0$ on both control and treatment areas, indicating a significant decline between years in use of the entire study area by pairs of barred owls that was not directly attributable to experimental removal activities.

- In the Oregon Coast Ranges study area, probability of use by barred owls was high in both years of the study in the control area $(>0.920)$, but declined by approximately $13 \%$ in the treatment area (0.792). Estimates of the annual rate of change in use $(\lambda)$ were $<1.0$ in the treatment area, but not in the control area, indicating strong support for treatment effect in the first year following initiation of removals.

- In the Klamath/Union/Myrtle study area, model-averaged estimates of the probability of use in the first year of pre-treatment surveys (2016) were slightly greater in the treatment relative to control areas, but evidence that use differed between these areas was weak during the first year of surveys.

- We observed transition in age-class of barred owls collected during the first 16 months of removals, with a substantially greater proportion of territorial subadults collected at sites where established resident adult pairs had been removed in previous months. This pattern would be expected if younger, recently produced first- and second-year birds were available to quickly fill breeding vacancies created by experimental removals.

- Overall, our preliminary assessment showed an equivocal response of spotted owls to experimental removals of barred owls in the first year following treatments, but sample sizes were small and estimates reported here do not account for uncertainties associated with imperfect detection rates. 


\section{Schedule to Completion}

\begin{tabular}{|c|c|}
\hline Year & Tasks \\
\hline Year $1(2015)$ & $\begin{array}{l}\text { - Survey both species on control and treatment areas (March-August). } \\
\text { - } \quad \text { Initiate removals of barred owls on designated treatment areas in Coast Ranges (COA) and } \\
\text { Cle Elum (CLE; September-December). } \\
\text { - } \quad \text { Year } 1 \text { progress report summarizing surveys and removals (February 2016). }\end{array}$ \\
\hline Year 2 (2016) & $\begin{array}{l}\text { - Continue removal of barred owls on COA and CLE treatment areas during the non- } \\
\text { breeding season (January-March ). } \\
\text { - Survey both species on control and treatment areas (March-August); initiate pre-treatment } \\
\text { surveys on Klamath/Union/Myrtle (KLA). } \\
\text { - Conduct removals of barred owls on designated treatment areas in COA and CLE; initiate } \\
\text { removals on KLA (September-December). } \\
\text { Year } 2 \text { progress report including a preliminary analysis of first-year treatment effects on } \\
\text { barred owls in COA and CLE (March 2017). }\end{array}$ \\
\hline Year 3 (2017) & $\begin{array}{l}\text { - } \quad \text { Conduct opportunistic removal of barred owls in all treatments (January-March). } \\
\text { - } \quad \text { Survey both species on control and treatment areas (March-August). } \\
\text { - } \quad \text { Conduct focused removals of barred owls from specific areas (April-August). } \\
\text { - } \quad \text { Conduct removals of barred owls in treatment areas (September-December). } \\
\text { - Year } 3 \text { progress report (March 2018). }\end{array}$ \\
\hline Year 4 (2018) & $\begin{array}{l}\text { - } \quad \text { Conduct opportunistic removal of barred owls (January-March). } \\
\text { - } \quad \text { Survey both species on control and treatment areas (March-August). } \\
\text { - } \quad \text { Conduct focused removals of barred owls from specific areas (April-August). } \\
\text { - } \quad \text { Conduct removals of barred owls in treatment areas (September-December). } \\
\text { - } 4 \text { progress report including a preliminary assessment of treatment effects on } \\
\text { occupancy, survival, and } \lambda_{t} \text { of spotted owls with data from } 3 \text { years of post-removal } \\
\text { surveys; determine study area-specific need to continue experiment for additional year(s) in } \\
\text { COA and CLE (March 2019). }\end{array}$ \\
\hline Year 5 (2019) & $\begin{array}{l}\text { - Conduct removals of barred owls on designated treatment areas (January-March). } \\
\text { - } \quad \text { Conduct opportunistic removals of barred owls on KLA (September-December). } \\
\text { - } \quad \text { Yearvey both species on control and treatment areas (March-August). } \\
\text { survival, and } \lambda_{t} \text { of spotted owls; determine need to continue experiment for additional } \\
\text { year(s) (March 2020). }\end{array}$ \\
\hline
\end{tabular}

\section{Acknowledgments}

We are indebted to Keith Bagnall, James Butch, Samantha Hanson, Jordan Hazen, Melissa Hunt, Matthew Landever, Clara Lebow, Matthew Nickols, Timothy Plawman, Suzanne Reffler, and Taylor Smith for their field assistance. Chris McCafferty, Stan Sovern, Aja Woodrow, and Rob Horn provided logistical assistance and survey data on spotted owls. We thank the many Federal, State, and private landowners who provided permission to access their lands and for providing logistical support essential to field activities and data collection. 


\section{References Cited}

Burnham, K.P., and Anderson, D.R., 2002, Model selection and multimodel inference-A practical information-theoretic approach (2nd ed.): New York, Springer-Verlag, 488 p.

Conner, M.M., Keane, J.J., Gallagher, C.V., Munton, T.E., and Shaklee, P.A., 2016, Comparing estimates of population change from occupancy and mark-recapture models for a territorial species: Ecosphere, , v. 7, no. 10, p. e01538.10.1002/ecs2.1538.

Diller, L.V., Dumbacher, J.P., Bosch, R.P., Bown, R.R., and Gutiérrez, R.J., 2014, Removing barred owls from local areas-Techniques and feasibility: Wildlife Society Bulletin, v. 38, p. 211-216.

Diller, L.V., Hamm, K.A., Early, D.A., Lamphear, D.W., Dugger, K.M., Yackulic, C.B., Schwarz, C.J., Carlson, P.C., and McDonald, T.L., 2016, Demographic response of northern spotted owls to barred owl removal: Journal of Wildlife Management, doi:10.1002/jwmg./1046.

Dugger, K.M., Forsman, E.D., Franklin, A.B., Davis, R.J., White, G.C., Schwarz, C.J., Burnham, K.P., Nichols, J.D., Hines, J.E., Yackulic, C.B., Doherty, P.F., Jr., Bailey, L., Clark, D.A., Ackers, S.H., Andrews, L.S., Augustine, B., Biswell, B.L., Blakesley, J., Carlson, P.C., Clement, Matthew, J., Diller, L.V., Glenn, E.M., Green, A., Gremel, S.A., Herter, D.R., Higley, J.M., Hobson, J., Horn, R.B., Huyvaert, K.P., McCafferty, C., McDonald, T., McDonnell, K., Olson, G.S., Reid, J.A., Rockweit, J., Ruiz, V., Saenz, J., and Sovern, S.G., 2016, The effects of habitat, climate and barred owls on long-term demography of northern spotted owls: The Condor-Ornithological Applications, v. 118, p. 57-116.

Franklin, A.B., Carlson, P.C., and Rockweit, J.T., 2015, Monitoring barred owls on the WCSA northern spotted owl demographic area-2015 progress report: Report to the U.S. Geological Survey, U.S. Department of Interior Interagency Agreement G15PG00030.

Holm, S.R., Noon, B.R., Wiens, J.D., and Ripple, W.J., 2016, Potential trophic cascades triggered by the barred owl range expansion: Wildlife Society Bulletin, v. 40, p. 615-624.

Hunt, W.G., 1998, Raptor floaters at Moffat's equilibrium: Oikos, v. 82, p. 191-197.

Johnson, D.H., White, G.C., Franklin, A.B., Diller, L.V., Blackburn, I., Pierce, D.J., Olson, G.S., Buchanan, J.B., Thrailkill, J., Woodbridge, B., and Ostwald, M., 2008, Study designs for barred owl removal experiments to evaluate potential effects on northern spotted owls: Olympia, Washington Department of Fish and Wildlife.

Lint, J.B, Noon, B.R., Anthony, R.G., Forsman, E.D., Raphael, M.G., Collopy, M., and Starkey, E., 1999, Northern spotted owl effectiveness monitoring plan for the Northwest Forest Plan: U.S. Forest Service, General Technical Report PNW-GTR-440.

MacKenzie, D.I., Nichols, J.D., J.E. Hines, M.D. Knutson, and A.B. Franklin, 2003, Estimating site occupancy, colonization, and local extinction when a species is detected imperfectly: Ecology, v. 84, p. 2200-2207.

MacKenzie, D.I., Nichols, J.D., Royle, J.A., Pollack, K.H., Bailey, L.L., and Hines, J.E., 2006, Occupancy estimation and modeling-Inferring patterns and dynamics of species occurrence: Burlington, Massachusetts, Academic Press, 324 p.

Penteriani, V., Ferrer, M., and Delgado, M.D.M, 2011, Floater strategies and dynamics in birds, and their importance in conservation biology-Towards an understanding of nonbreeders in avian populations: Animal Conservation, v. 14, p. 233-241.

U.S. Fish and Wildlife Service, 2013, Experimental removal of barred owl to benefit threatened northern spotted owls - Final environmental impact statement: U.S. Department of Interior, Portland, Oregon, $467 \mathrm{p}$.

U.S. Fish and Wildlife Service, 2015, Draft interim guidance for conducting barred owl surveys within the range of the northern spotted owl-For use in experimental removal studies and determining abundance: U.S. Department of Interior, Portland, Oregon. 
Weidensaul, C.S., Colvin, B.A., Brinker, D.R., and Huy, J.S., 2011, Use of ultraviolet light as an aid in age classification of owls: The Wilson Journal of Ornithology, v. 123, p. 373-377.

White, G.C., and Burnham, K.P., 1999, Program MARK-Survival estimation from populations of marked animals: Bird Study, v. 46, p. 120-138.

Wiens, J.D., Anthony, R.G., and Forsman, E.D., 2011, Barred owl occupancy surveys within the range of the northern spotted owl: Journal of Wildlife Management, v. 75, p. 531-538.

Wiens, J.D., Anthony, R.G., and Forsman, E.D., 2014, Competitive interactions and resource partitioning between northern spotted owls and barred owls in western Oregon: Wildlife Monographs, v. 185, p. $1-51$.

Wiens, J.D., Dugger, K.M., Lewicki, K.E., and Simon, D.C., 2016, Effects of experimental removal of barred owls on population demography of northern spotted owls in Washington and Oregon-2015 progress report: U.S. Geological Survey Open-File Report 2016-1041, p. 1-16.

Yackulic, C.B., Reid, J., Nichols, J.D., Hines, J.E., Davis, R., and Forsman, E., 2014, The roles of competition and habitat in the dynamics of populations and species distributions: Ecology, v. 95, p. $265-279$. 


\section{Appendix A. Distribution of Pairs of Northern Spotted Owls and Barred Owls in Three Experimental Study Areas in Washington and Oregon, 2015-16}

We show historical territories of spotted owls in control and treatment areas relative to the distribution of pairs of spotted owls and barred owls detected during surveys in 2015 and 2016.

2015
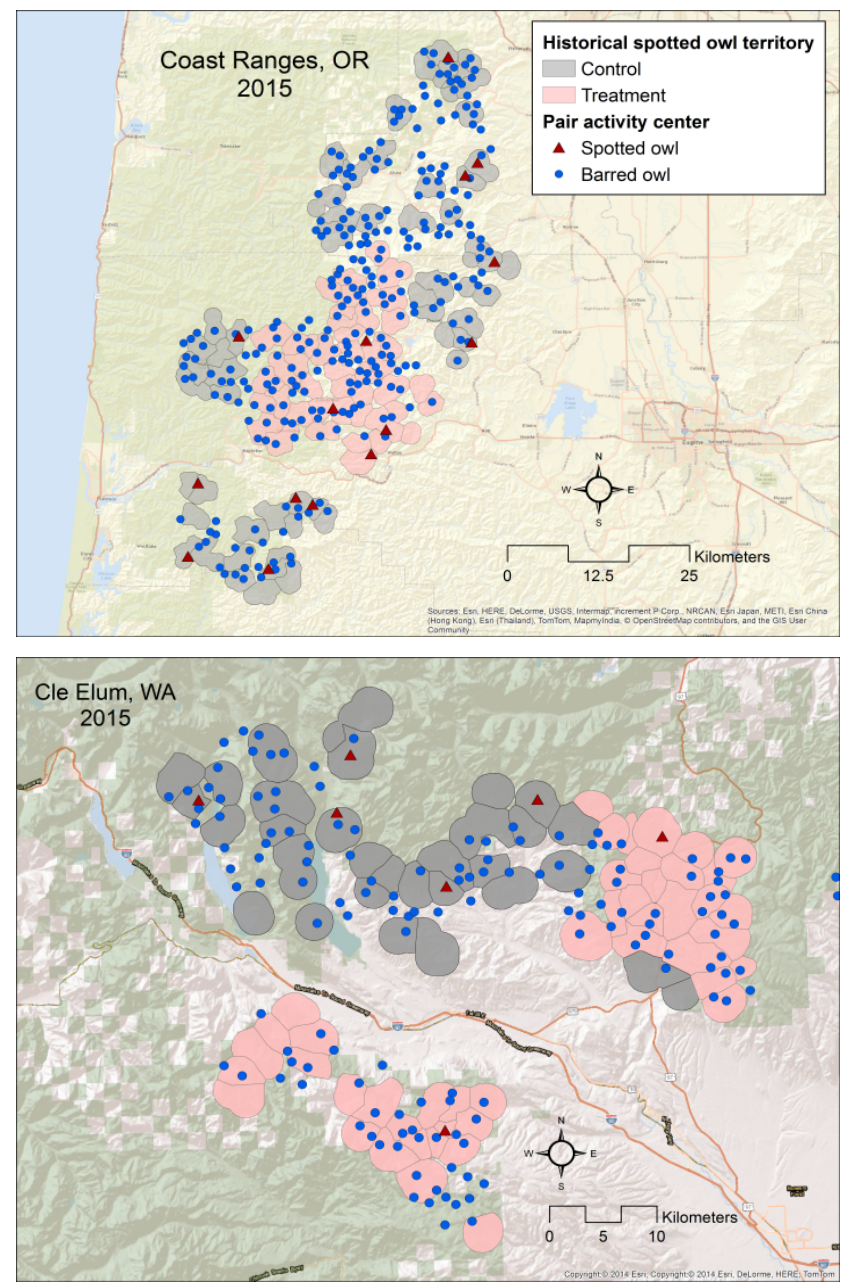

2016
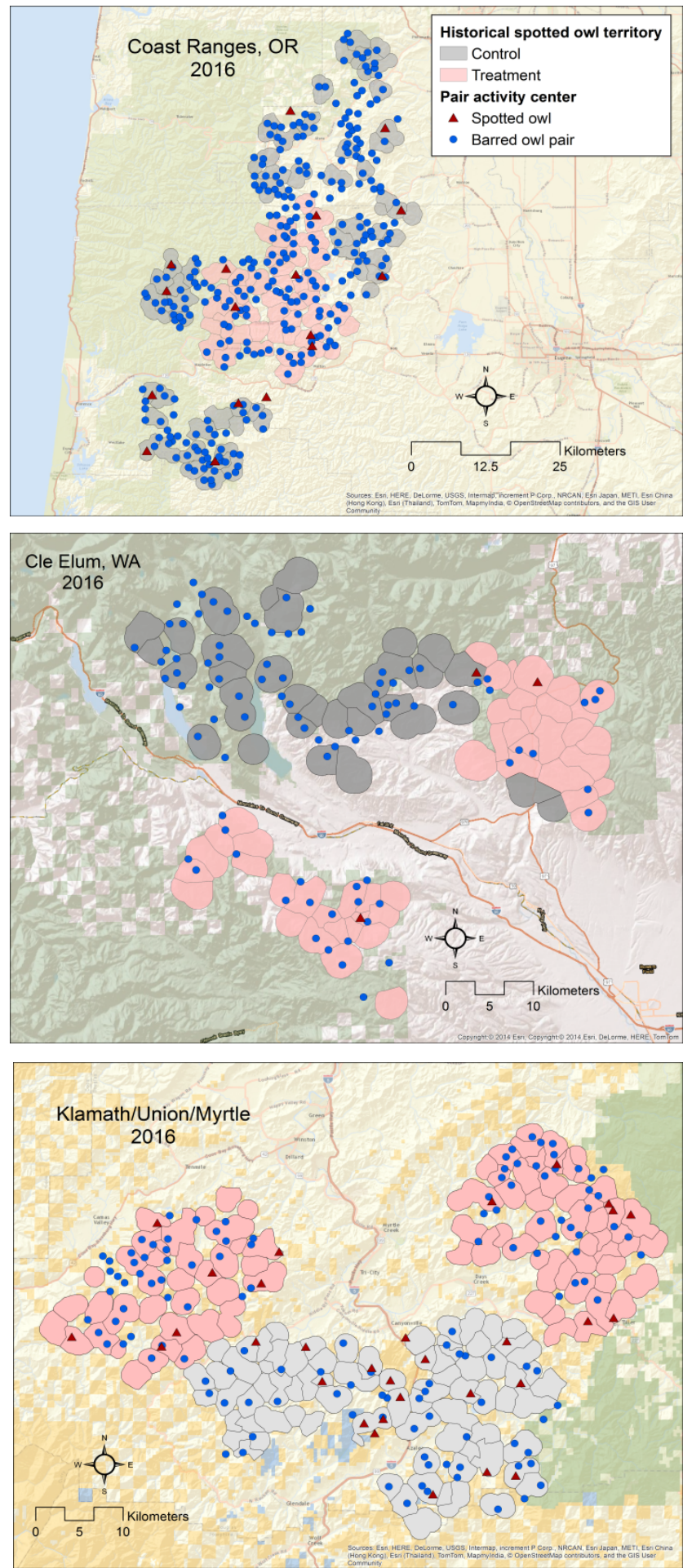


\section{Appendix B. Model Selection Results for the Analysis of Probabilities of Use $(\psi)$, Extinction $(\varepsilon)$, Colonization $(\gamma)$, and Detection $(p)$ of Barred Owls on the Cle Elum Experimental Study Area, Washington, 2015-16}

Model parameters are defined as follows: $\psi=$ probability of use in the first year of study (initial occupancy), $\varepsilon=$ the probability that a previously used site was not used in the subsequent year (extinction), $\gamma=$ the probability that a previously vacant site was colonized in the subsequent year (colonization), and $p=$ the probability of detection. Models with area effects allow parameter estimates to vary between treatment (removal) and control areas. Time effects on detection are modeled as constant (.), varying with survey period (occasion), or year. $\mathrm{AIC}_{c}=$ Akaike's Information Criterion for small sample size, $\Delta \mathrm{AIC}_{c}=$ difference between the $\mathrm{AIC}_{c}$ value of each model and the lowest $\mathrm{AIC}_{c}$ model, Deviance is defined as the difference in $-2[\operatorname{loge}($ Likelihood)] of the current model and $2[\operatorname{loge}($ Likelihood)] of the saturated model.

\begin{tabular}{|c|c|c|c|c|c|}
\hline Modeling step & $\mathrm{AICc}$ & Delta AICc & AICc Weights & Num. Par & Deviance \\
\hline \multicolumn{6}{|c|}{ 1. Treatment and time effects on detection $(p)$} \\
\hline$p$ (area, year) & 972.057 & 0.000 & 0.690 & 10 & 951.551 \\
\hline$p$ (area, year, occasion) & 975.604 & 3.547 & 0.117 & 18 & 938.002 \\
\hline$p$ (occasion) & 976.947 & 4.890 & 0.060 & 9 & 958.534 \\
\hline$p$ (year, occasion) & 976.981 & 4.925 & 0.059 & 12 & 952.261 \\
\hline$p$ (area, occasion) & 977.185 & 5.129 & 0.053 & 12 & 952.465 \\
\hline$p$ (area) & 979.683 & 7.626 & 0.015 & 8 & 963.353 \\
\hline$p()$. & 981.551 & 9.494 & 0.006 & 7 & 967.295 \\
\hline \multicolumn{6}{|c|}{$\begin{array}{l}\text { 2. Treatment effects on use }(\psi) \text {,extinction }(\varepsilon) \text {, } \\
\text { and colonization }(\gamma)\end{array}$} \\
\hline$\psi(.) \varepsilon(.) \gamma()$. & 967.289 & 0.000 & 0.431 & 7 & 953.034 \\
\hline$\psi(.) \varepsilon(.) \gamma($ area $)$ & 968.727 & 1.438 & 0.210 & 8 & 952.398 \\
\hline$\psi(.) \varepsilon($ area $) \gamma()$. & 968.752 & 1.463 & 0.208 & 8 & 952.423 \\
\hline$\psi(.) \varepsilon($ area $) \gamma($ area $)$ & 970.004 & 2.715 & 0.111 & 9 & 951.591 \\
\hline$\psi($ area $) \varepsilon($ area $) \gamma($ area $)$ & 972.057 & 4.767 & 0.040 & 10 & 951.551 \\
\hline
\end{tabular}




\section{Appendix C. Model Selection Results for the Analysis of Probabilities of Use $(\psi)$, Extinction $(\varepsilon)$, Colonization $(\gamma)$, and Detection $(p)$ of Barred Owls on the Coast Ranges Experimental Study Area, Oregon, 2015-16}

Multi-season occupancy model parameters are defined as follows: $\psi=$ probability of use in the first year of study (initial occupancy), $\varepsilon=$ the probability that a previously used site was not used in the subsequent year (extinction), $\gamma=$ the probability that a previously vacant site was colonized in the subsequent year (colonization), and $p=$ the probability of detection. Models with area effects allow parameter estimates to vary between treatment (removal) and control areas. Time effects on detection are modeled as constant (.), varying with survey period (occasion), or year.

\begin{tabular}{|c|c|c|c|c|c|}
\hline Modeling step & AICc & Delta AICc & AICc Weights & Num. Par & Deviance \\
\hline \multicolumn{6}{|c|}{ 1. Treatment and time effects on detection $(p)$} \\
\hline$p$ (year, occasion $)$ & 1514.450 & 0.000 & 0.636 & 12 & 1489.878 \\
\hline$p$ (area, year, occasion) & 1516.250 & 1.801 & 0.258 & 18 & 1478.984 \\
\hline$p$ (area, occasion $)$ & 1519.166 & 4.716 & 0.060 & 12 & 1494.594 \\
\hline$p$ (occasion) & 1519.797 & 5.347 & 0.044 & 9 & 1501.469 \\
\hline$p$ (area, year) & 1527.591 & 13.141 & 0.001 & 10 & 1507.189 \\
\hline$p()$. & 1528.977 & 14.528 & 0.000 & 7 & 1514.774 \\
\hline$p($ area $)$ & 1530.531 & 16.081 & 0.000 & 8 & 1514.269 \\
\hline \multicolumn{6}{|c|}{$\begin{array}{l}\text { 2. Treatment effects on use }(\psi) \text {,extinction }(\varepsilon) \text {, } \\
\text { and colonization }(\gamma)\end{array}$} \\
\hline$\psi(.) \varepsilon($ area $) \gamma()$. & 1511.674 & 0.000 & 0.578 & 10 & 1491.272 \\
\hline$\psi(.) \varepsilon($ area $) \gamma($ area $)$ & 1513.435 & 1.761 & 0.239 & 11 & 1490.953 \\
\hline$\psi($ area) $\varepsilon$ (area) $\gamma$ (area) & 1514.450 & 2.776 & 0.144 & 12 & 1489.878 \\
\hline$\psi(.) \varepsilon(.) \gamma()$. & 1518.244 & 6.570 & 0.022 & 9 & 1499.916 \\
\hline$\psi(.) \varepsilon(.) \gamma($ area $)$ & 1518.690 & 7.016 & 0.017 & 10 & 1498.288 \\
\hline
\end{tabular}




\section{Appendix D. Model Selection Results for the Single-Season Analysis of Probabilities of Use $(\psi)$ and Detection ( $p$ ) of Barred Owls on the Klamath/Union/Myrtle Experimental Study Area, Oregon, 2016}

Single-season occupancy model parameters are defined as follows: $\psi=$ the probability of $\geq 1$ pairs of barred owls using a sampling unit (500-hectare hexagon) during the survey season (March-September); $p=$ the probability of detecting $\geq 1$ barred owl at sampling unit $\mathrm{i}$ during survey occasion $\mathrm{t}$, given presence. Models with area effects allow parameter estimates to vary between treatment and control areas. Time effects are modeled as constant (.), varying with survey occasion (t), or increasing from the survey Period 1 to Period 3 (T).

\begin{tabular}{|c|c|c|c|c|c|}
\hline Model & $\mathrm{AICC}$ & Delta AICc & AICc Weights & Num. Par & Deviance \\
\hline$\psi($ area $) p(\mathrm{t})$ & 709.666 & 0.000 & 0.499 & 5 & -554.981 \\
\hline$\psi() p.(\mathrm{t})$ & 710.457 & 0.792 & 0.336 & 4 & -552.112 \\
\hline$\psi($ area $) p(\mathrm{~T})$ & 713.287 & 3.621 & 0.082 & 4 & -549.283 \\
\hline$\psi() p.(\mathrm{~T})$ & 713.952 & 4.287 & 0.059 & 3 & -546.556 \\
\hline$\psi() p.($ area $)$ & 716.964 & 7.298 & 0.013 & 3 & -543.545 \\
\hline$\psi($ area $) p($ area $)$ & 719.021 & 9.356 & 0.005 & 4 & -543.548 \\
\hline$\psi($ area $) p()$. & 719.433 & 9.767 & 0.004 & 3 & -541.076 \\
\hline$\psi() p.()$. & 720.034 & 10.368 & 0.003 & 2 & -538.429 \\
\hline
\end{tabular}



Publishing support provided by the U.S. Geological Survey Science Publishing Network, Tacoma Publishing Service Center

For more information concerning the research in this report, contact the Director, Forest and Rangeland Ecosystem Science Center U.S. Geological Survey

777 NW 9th St., Suite 400

Corvallis, Oregon 97330

http://fresc.usgs.gov/ 
